\title{
Adubação do algodão colorido BRS 200 em sistema orgânico no Seridó Paraibano
}

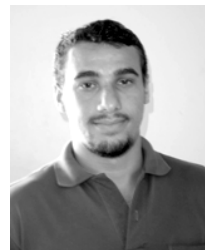

Melchior N. B. da Silva1 ${ }^{1}$ Napoleão E. de M. Beltrão² \& Gleibson D. Cardoso²

\author{
1 EMBRAPA Algodão, Rua Oswaldo Cruz, 1143, Centenário, CP 174, Campina Grande,PB, CEP 58107-720. \\ Fone: (83) 3315-4352, E-mail: melchior@cnpa.embrapa.br (Foto) \\ 2 EMBRAPA Algodão. Fone: (83) 3315-4352, E-mail: nbeltrao@cnpa.embrapa.br, gleibson@cnpa.embrapa.br
}

Protocolo $201-17 / 12 / 2003$ - Aprovado em 30/7/2004

\begin{abstract}
Resumo: É grande a potencialidade do algodão colorido para ser cultivado organicamente na região semi-árida, onde as condições edafoclimáticas possibilitam o cultivo sem defensivos agrícolas. Os adubos orgânicos têm sido utilizados para melhorar as propriedades físico-químicas do solo, o estabelecimento de microrganismos benéficos e o aumento da matéria orgânica, além de ser fonte de nutrientes. O objetivo deste trabalho foi determinar níveis e forma de aplicação do esterco bovino em algodoeiro colorido BRS 200-marrom, cultivado sob manejo orgânico nas condições edafoclimáticas do Seridó Paraibano. O experimento foi conduzido em blocos ao acaso, com nove tratamentos e quatro repetições, nos anos 2000, 2001 e 2002. Os tratamentos se originaram de um fatorial $(4 \times 2+1)$, cujos fatores foram quatro níveis de esterco bovino curtido $\left(10,20,30\right.$ e $40 \mathrm{t} \mathrm{ha}^{-1}$ ) em dois locais de aplicação (abaixo e ao lado das sementes), adicionado de uma testemunha absoluta sem adubação orgânica. A presença do esterco bovino incrementou a produtividade do algodão. Quando ocorreu regularidade climática, a aplicação ao lado das sementes foi mais eficiente, alcançando-se o máximo rendimento com $30 \mathrm{t} \mathrm{ha}^{-1}$. A uniformidade do comprimento da fibra decresceu e o índice de fibras curtas aumentou com o incremento dos níveis de adubo.
\end{abstract}

Palavras-chave: Gossypium hirsutum, adubação orgânica, agricultura orgânica, esterco bovino

\section{Fertilization of colored cotton BRS 200 under organic system in Serido, in the State of Paraiba, Brazil}

\begin{abstract}
The naturally colored cotton has potentiality for growth in Northeast Semi-arid, where the edaphoclimatic conditions permit the cultivation without agrochemicals. Organic fertilizers have been used to improve physico-chemical properties of the soil, establishment of beneficial microorganisms, increase of the organic matter and nutrients. The objective of this work was to determine levels and forms of application of cattle manure in colored cotton BRS 200, cultivated under organic management in Seridó, in the State of Paraiba. The experiment was conducted in randomized blocks, with nine treatments and four replications, during 2000, 2001 and 2002. The treatments were originated from a factorial $4 \times 2+1$, consisting of four levels of decomposed cattle manure $\left(10,20,30\right.$ and $40 \mathrm{t} \mathrm{ha}^{-1}$ ) and two sites of application (below and by the side of seeds), plus an absolute control without organic manure. Organic fertilization increased the cotton yield. Under regular climatic conditions, the sidewise application was more efficient, reaching the maximum yield with $30 \mathrm{t} \mathrm{ha}^{-1}$. The uniformity of fiber length decreased and the index of short fibers increased with the increment of the levels of organic manure.
\end{abstract}

Key words: Gossypium hirsutum, organic manure, organic farming, cattle manure

\section{INTRODUÇÃO}

O algodão colorido BRS 200 de fibra marrom tem apresentado excelente potencial de cultivo no semi-árido nordestino, onde as condições edafoclimáticas possibilitam a sua exploração sem o uso de defensivos agrícolas (Santana et al., 1999), condição requerida nos sistemas orgânicos. A presença de pigmentos naturais em suas fibras elimina a necessidade de tintura com corantes sintéticos, diminuindo os impactos ambientais (Buschle-Diller et al., 1998). O algodão orgânico é aquele produzido e processado com métodos e materiais menos agressivos ao ambiente, sendo proibido o uso de pesticidas 
sintéticos de alta toxicidade e persistência, irradiações ionizantes, organismos geneticamente modificados, fertilizantes sintéticos, reguladores do crescimento e resíduos de esgoto (Marquardt, 2003). O uso desta tecnologia minimiza os perigos com poluentes agrícolas (pesticidas e fertilizantes sintéticos), da indústria têxtil (corantes sintéticos carcinogênicos), resíduos de pesticidas nas fibras e restaura ou preserva o equilíbrio entre os diferentes componentes do ecossistema. Além disso, pode reduzir os custos de produção e aproveitar a mão-de-obra familiar (Rajendran et al., 2003)

A fertilização de culturas é um dos maiores desafios da agricultura orgânica, sendo necessário o conhecimento aprimorado dos ciclos dos nutrientes para se adotar as práticas de manejo mais adequadas. A eficiência no fluxo de nutrientes que estão imobilizados para a solução do solo, é essencial para a manutenção da fertilidade nos sistemas orgânicos. Para garantir máximas produtividades, deve-se manter satisfatório nível de nitrogênio e demais elementos essenciais, além de altos níveis de matéria orgânica. Para isso, utilizam-se adubação orgânica, rotação e associação de culturas e fixação biológica de nitrogênio atmosférico pelas bactérias associadas a leguminosas (Altieri, 1989; Klonsky et al., 1996).

Bulluck et al. (2002) afirmam que compostos orgânicos usados como melhoradores alternativos da fertilidade do solo, podem resultar em incremento da matéria orgânica e atividade biológica do solo. Conforme os resultados desses autores, condicionadores orgânicos de solo como o esterco bovino e o composto de caroço de algodão, podem ser superiores aos fertilizantes sintéticos, por melhorarem os atributos biológicos, físicos e químicos do solo, incrementando a produtividade das plantas. Para Bulluck \& Ristaino (2002), o uso de melhoradores alternativos do solo pode resultar em melhoria da qualidade do solo e no controle de doenças de plantas.

O emprego de fertilizantes orgânicos está associado, também, à melhoria das propriedades do solo, como também da retenção de água, propriedades físicas e estabelecimento de microrganismos benéficos (Doran, 1995; Drinkwater et al., 1995), redução da população de patógenos, aumento da matéria orgânica do solo e da capacidade de troca de cátions e diminuição da densidade do solo (Bulluck et al., 2002). Nesses benefícios ainda se incluem estabilização do $\mathrm{pH}$, melhoria na taxa de infiltração e agregação do solo (Stamatiadis et al., 1999; Lima, 2001). Enfim, a adição de compostos orgânicos tem contribuído para a excelência da qualidade do solo, que especialmente nos cultivos orgânicos tem promovido sustentabilidade nesse sistema de produção.

Plantadores de algodão orgânico na Califórnia, EUA, incorporam compostos orgânicos animais como fonte de matéria orgânica, fósforo, potássio e outros nutrientes (Klonsky et al., 1996). Em estudo realizado no município de Tauá, CE, região semi-árida do Nordeste brasileiro, Lima (2001) verificou que o esterco animal promoveu a melhoria das características químicas do solo cultivado com algodão orgânico, principalmente pelo aumento nos teores de carbono, fósforo, soma de bases e diminuição da relação $\mathrm{C} / \mathrm{N}$.

Apesar de alguns trabalhos enfatizarem o uso de adubação orgânica em algodoeiro (Medeiros, 1991; Beltrão et al., 2001), os insumos orgânicos geralmente têm sido manejados de forma empírica, sobretudo no que concerne aos processos de decomposição e do fluxo de nutrientes do solo (Swift, 1999; Souto, 2002). Esses processos estão intimamente ligados à biota do solo, sendo de vital importância a renovação da matéria orgânica para o estabelecimento e atividade dos microrganismos. Um dos adubos orgânicos mais utilizados na agricultura nordestina é o esterco, principalmente caprino, ovino e bovino, porém sua eficiência depende do grau de decomposição, da origem do material, da dosagem empregada e até da forma de colocação do adubo.

Objetivou-se, com este trabalho, determinar nível e forma de aplicação do esterco bovino em algodoeiro colorido BRS 200-marrom, cultivado sob manejo orgânico nas condições edafoclimáticas do Seridó Paraibano.

\section{MATERIAL E MÉTODOS}

O experimento foi conduzido na Estação Experimental de Patos, situada na região fisiográfica do Seridó Paraibano, no Estado da Paraíba, onde o clima é tipo BS (semi-árido) na classificação de Köppen. O município de Patos está situado nas coordenadas geográficas de $7^{\circ} 01^{\prime}$ de latitude sul e $37^{\circ} 06^{\prime}$ de longitude oeste, a uma altitude de $249,4 \mathrm{~m}$. Os dados de precipitação pluviais estão dispostos na Figura 1.

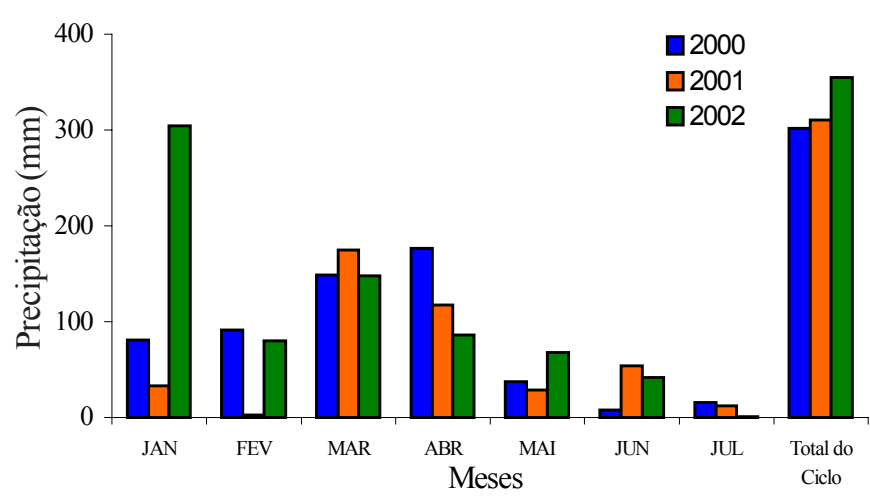

Figura 1. Dados pluviométricos da área experimental. Patos, 2000,2001 e 2002

O plantio foi realizado nos dias 10/3, 14/3 e 15/2 nos anos de 2000, 2001 e 2002, respectivamente, no espaçamento de 1,0 x $0,5 \mathrm{~m}$ com 1 planta por cova, ou seja, uma população de 20.000 plantas ha $^{-1}$. No ano 2000 foi cultivada a linhagem CNPA $772 / 1139$, um dos materiais que deram origem à cultivar BRS 200, de fibras marrom, cultivada nos anos de 2001 e 2002. Esta cultivar foi produzida pelo Centro Nacional de Pesquisa do Algodão proveniente de seleção de materiais asselvajados de algodão arbóreo (Gossypium barbadense L. Gossypium hirsutum L. raça marie galante Hutch.) (Freire et al., 1997).

O solo do local é de textura arenosa e foi identificado como Luvissolo (EMBRAPA, 1999) tendo como vegetação predominante caatinga hiperxerófila, apresentando relevo suave ondulado. Os atributos químicos do solo da área experimental estão dispostos na Tabela 1 . O solo quanto a textura, em média apresenta, areia grossa, areia fina, silte e argila, respectivamente, $482,271,148,99 \mathrm{~g} \mathrm{~kg}^{-1} \mathrm{e}$ densidade aparente e real igual a $1,46 \mathrm{e} 2,49 \mathrm{~kg} \mathrm{dm}^{-3}$. 
Tabela 1. Características físico-químicas do solo da área experimental

\begin{tabular}{|c|c|c|c|c|c|c|c|c|c|c|c|c|c|c|c|}
\hline \multirow{3}{*}{ Anos } & \multicolumn{8}{|c|}{ Análise Química } & \multicolumn{7}{|c|}{ Análise Física } \\
\hline & \multirow{2}{*}{$\begin{array}{c}\mathrm{pH} \\
(1: 25)\end{array}$} & $\mathrm{Ca}^{+2}$ & $\mathrm{Mg}^{+2}$ & $\mathrm{Na}^{+}$ & $\mathrm{K}^{+}$ & $\mathrm{Al}^{+3}$ & \multirow{2}{*}{$\frac{P}{\mathrm{mg} \mathrm{dm}^{-3}}$} & \multirow{2}{*}{$\begin{array}{l}\text { M.O. } \\
\mathrm{g} \mathrm{kg}^{-1}\end{array}$} & \multicolumn{3}{|c|}{ Textura $\left(\mathrm{g} \mathrm{kg}^{-1}\right)$} & \multicolumn{3}{|c|}{ Densidade $\left(\mathrm{kg} \mathrm{dm}^{-3}\right)$} & \multirow{2}{*}{$\begin{array}{c}\mathrm{PT} \\
\left(\mathrm{m}^{3} \mathrm{~m}^{3}\right)\end{array}$} \\
\hline & & & & $\mathrm{ol}_{\mathrm{c}} \mathrm{d}$ & & & & & $\mathrm{AG}$ & $\mathrm{AF}$ & Silte & \multirow{2}{*}{$\begin{array}{c}\text { Argila } \\
99\end{array}$} & \multirow{2}{*}{$\begin{array}{c}\text { Global } \\
1,46\end{array}$} & \multirow{2}{*}{$\begin{array}{l}\text { Real } \\
2,49\end{array}$} & \\
\hline 2000 & 6,3 & 28,0 & 3,0 & 0,6 & 4,2 & 0,5 & 17,25 & 8,17 & 482 & 271 & 148 & & & & 0,4148 \\
\hline 2001 & 6,5 & 30,0 & 7,0 & 1,2 & 4,0 & 0,5 & 8,56 & 8,02 & & & & & & & \\
\hline 2002 & 6,9 & 35,0 & 11,0 & 0,4 & 4,1 & 0,0 & 10,5 & 9,24 & & & & & & & \\
\hline
\end{tabular}

AG - Areia Grossa; AF - Areia Fina; PT - Porosidade Total

O desbaste foi realizado 30 dias após o plantio, com a finalidade de se adequar a população de plantas. Por se tratar de um cultivo orgânico, o controle de ervas daninhas foi realizado com cultivador de tração animal, seguido de retoques com enxada manual, sempre que houvesse competição entre o algodão e os inços. Para o controle do bicudo (Anthonomus grandis Boheman 1843) aplicou-se o fungo Beauveria bassiana, na dose de $1 \times 10^{8}$ conídeos $\mathrm{mL}^{-1}$ da formulação oleosa contendo $70 \%$ de óleo de soja e $30 \%$ de querosene (Silva, 2001). Um dos aspectos mais significativos no controle desta praga, foi o ambiente, já que a região fisiográfica do Seridó Paraibano apresenta condições inóspitas ao desenvolvimento do bicudo do algodoeiro.

O delineamento experimental utilizado foi o de blocos ao acaso, com nove tratamentos e quatro repetições. Os tratamentos se originaram de um fatorial $(4 \times 2+1)$, sendo os fatores quatro níveis de esterco bovino curtido $(10,20,30$ e 40 $\mathrm{t} \mathrm{ha}^{-1}$ ) em base úmida em dois locais de aplicação (abaixo e ao lado das sementes), adicionado de uma testemunha absoluta sem adubação orgânica. O adubo foi aplicado aproximadamente $10 \mathrm{~cm}$ de distância tanto "abaixo" quanto "ao lado" das sementes. A área total de cada unidade experimental foi de 24 $\mathrm{m}^{2}(6,0 \times 4,0 \mathrm{~m})$ com área útil de $10 \mathrm{~m}^{2}(5,0 \times 2,0 \mathrm{~m})$. Os resultados da análise físico-química do esterco bovino encontram-se na Tabela 2.

As variáveis analisadas foram algodão em caroço $\left(\mathrm{kg} \mathrm{ha}^{-1}\right)$; número de capulhos por planta; altura de plantas $(\mathrm{cm})$; percentagem de fibra (\%); peso de 1 capulho (g) e características tecnológicas de fibra e fio. Essas variáveis foram obtidas a partir da amostra padrão coletada por ocasião da colheita e as mensurações efetuadas no Laboratório de Fibras e Fios da EMBRAPA Algodão, conforme recomendação de Santana et

Tabela 2. Dados dos atributos físico-químicos do esterco bovino utilizado na adubação orgânica, nos anos de 2000 a 2002

\begin{tabular}{cccc}
\hline Atributos & 2000 & 2001 & 2002 \\
\hline Umidade & 7,28 & 10,25 & 5,39 \\
$\mathrm{pH}(1: 25)$ & 8,1 & 8,2 & 6,35 \\
Orgânica \% & 18,65 & 56,96 & 14,76 \\
Mineral \% & 74,07 & 32,79 & 79,85 \\
$\mathrm{C} \%$ & - & 31,64 & - \\
$\mathrm{N} \%$ & 1,07 & 1,13 & 1,04 \\
$\mathrm{P}_{2} \mathrm{O}_{5} \%$ & 1,54 & 1,24 & 1,68 \\
$\mathrm{~K}_{2} \mathrm{O} \%$ & 2,16 & 3,20 & 1,27 \\
$\mathrm{CaO} \%$ & 1,22 & 1,25 & 1,19 \\
$\mathrm{MgO} \%$ & 1,83 & 2,32 & 0,75 \\
$\mathrm{Relação} \mathrm{C/N}$ & - & $28 / 1$ & - \\
\hline
\end{tabular}

al. (1998). As características tecnológicas de fibra avaliadas foram: índice micronaire (Mic) em $\mu \mathrm{g} \mathrm{in}{ }^{-1}$ (microgramas por polegada); comprimento da fibra (Len) em mm; uniformidade de comprimento (Unf) em \%; índice de fibras curtas (SFI) em $\%$; resistência de fibras (Str) em gf tex ${ }^{-1}$; alongamento à ruptura (Elg) em \%; e reflectância (Rd) - quantidade de luz refletida pela fibra em $\%$.

Os dados foram submetidos a análise de variância e conseqüente análise de regressão do fator níveis de esterco bovino, conforme recomendações de Ferreira (2000) e Gill (1990).

\section{RESULTADOS E DISCUSSÃO}

Os resultados da análise de variância dos dados das variáveis agronômicas referentes aos anos de 2000, 2001 e 2002, estão dispostos nas Tabelas 3, nas quais se verifica efeito significativo a $1 \%$ de probabilidade pelo teste $\mathrm{F}$, para a variável rendimento em caroço, nos três anos da pesquisa, quando se avaliou o contraste entre o fatorial e a testemunha, ou seja, entre a aplicação de esterco bovino e sua ausência. Em 2002, houve efeito de doses para a variável rendimento de algodão em caroço. A altura de plantas em 2000, o peso médio de 1 capulho em 2001 e o número de capulhos por planta em 2002, também obtiveram resultados similares. A variável percentagem de fibra não foi influenciada pelos tratamentos adotados em nenhum dos anos em que a pesquisa foi realizada.

Devido à baixa fertilidade, principalmente baixo teor de matéria orgânica do solo, a aplicação de esterco bovino promoveu melhoria considerável na produtividade do algodoeiro colorido submetido ao manejo orgânico (Tabela 4), indicando que ações simples de manejo podem determinar o sucesso desse sistema de cultivo. Além de funcionar como fonte de nutrientes (Klonsky et al., 1996; Lima, 2001), os condicionadores orgânicos promovem melhoria na retenção de água e nas propriedades físicas do solo (Doran, 1995), fatores importantes para o agroecossistema estudado, já que foi freqüente a irregularidade pluviométrica com veranicos superiores a 20 dias.

Medeiros (1991) cultivando algodão em solo Bruno Não Cálcico, verificou aumento da produtividade do algodão quando adubado com $20 \mathrm{t} \mathrm{ha}^{-1}$ de esterco de curral. Segundo Stewart \& Robinson (1996) citados por Souto (2002), as práticas e o manejo de agricultura sustentável são mais difíceis em regiões áridas e semi-áridas, devido aos efeitos do clima (altas temperaturas e baixas precipitações), através da redução de biomassa e baixo retorno de carbono. 
Tabela 3. Resumo das análises de variância do rendimento em caroço $\left(\mathrm{kg} \mathrm{ha}^{-1}\right)$, altura de planta ( $\left.\mathrm{cm}\right)$, percentagem de fibra e peso de 1 capulho (g) do algodão colorido BRS 200-marrom sob manejo orgânico, em função de níveis de esterco e locais de aplicação

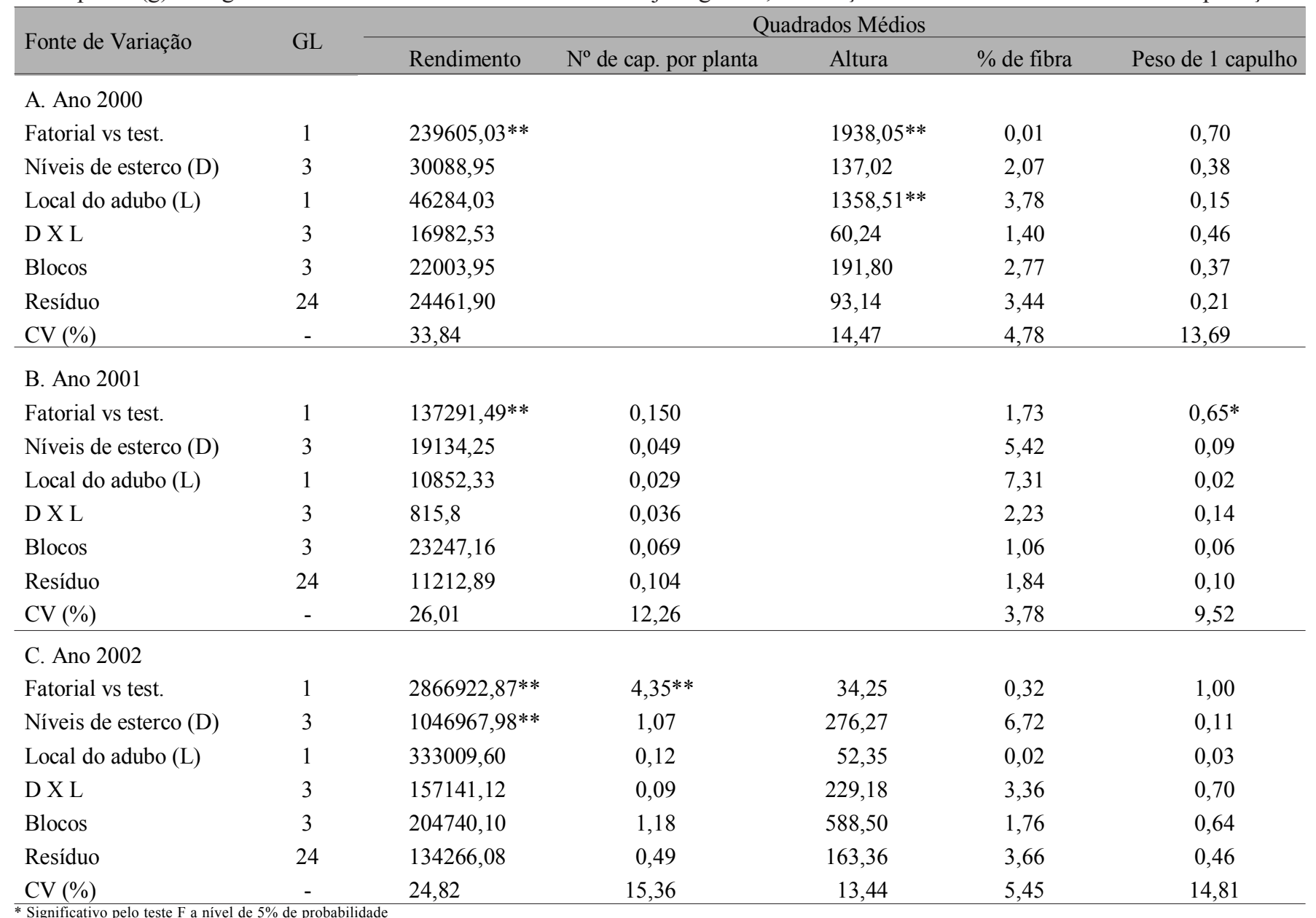

* Significativo pelo teste $\mathrm{F}$ a nível de $5 \%$ de probabilidade

** Significativo pelo teste $\mathrm{F}$ a nível de $1 \%$ de probabilidade

Tabela 4. Médias do rendimento em caroço, altura de plantas, peso de 1 capulho e número de capulhos por planta em algodoeiro BRS 200 - marrom, sob manejo orgânico, em função da adubação orgânica

\begin{tabular}{|c|c|c|c|c|c|c|}
\hline \multirow[b]{2}{*}{ Tratamentos } & \multicolumn{2}{|c|}{2000} & \multicolumn{2}{|c|}{2001} & \multicolumn{2}{|c|}{2002} \\
\hline & $\begin{array}{l}\text { Rendimento em } \\
\text { caroço* }\left(\mathrm{kg} \mathrm{ha}^{-1}\right)\end{array}$ & $\begin{array}{c}\text { Altura de } \\
\text { plantas* }(\mathrm{cm})\end{array}$ & $\begin{array}{l}\text { Rendimento em } \\
\text { caroço* }\left(\mathrm{kg} \mathrm{ha}^{-1}\right)\end{array}$ & $\begin{array}{c}\text { Peso de } 1 \\
\text { capulho** (g) }\end{array}$ & $\begin{array}{l}\text { Rendimento em } \\
\text { caroço* }\left(\mathrm{kg} \mathrm{ha}^{-1}\right)\end{array}$ & 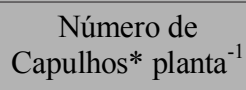 \\
\hline Testemunha sem adubo & $211,2 b$ & $44,2 \mathrm{~b}$ & $210,61 \mathrm{~b}$ & $2,92 \mathrm{~b}$ & $678,33 \mathrm{~b}$ & $3,57 \mathrm{~b}$ \\
\hline Fatorial com adubo & $470,8 \mathrm{a}$ & $67,5 \mathrm{a}$ & $407,11 \mathrm{a}$ & $3,35 \mathrm{a}$ & $1576,18 \mathrm{a}$ & $4,67 \mathrm{a}$ \\
\hline Abaixo da semente & 508,9 a & $74,0 \mathrm{a}$ & $402,97 \mathrm{a}$ & 3,12 & $1474,08 \mathrm{a}$ & $4,62 \mathrm{a}$ \\
\hline Ao lado da semente & $432,8 \mathrm{a}$ & $61,0 \mathrm{~b}$ & $411,12 \mathrm{a}$ & 3,59 & $1678,29 \mathrm{a}$ & $4,74 \mathrm{a}$ \\
\hline
\end{tabular}

Médias seguidas de mesma letra não diferem entre si pelo teste $\mathrm{F}$ a $1 \%$ de significância

*" Médias seguidas de mesma letra não diferem entre si pelo teste $\mathrm{F}$ a $5 \%$ de significância

A adição de esterco bovino incrementou em 122,92, 93,30 e $132,36 \%$ a produtividade média do algodoeiro colorido em 2000 , 2001 e 2002, respectivamente, em relação à testemunha (Tabela 4). No ano 2002 a produtividade média do algodão não adubado com esterco bovino foi superior às produtividades dos plantios onde foi empregado o adubo orgânico em 2000 e 2001. Apesar do esterco bovino ter promovido aumento no rendimento, a precipitação pluviométrica constituiu-se no fator mais importante para que o algodoeiro expressasse o seu potencial produtivo.

Por se tratar de um fatorial envolvendo um fator quantitativo, a interação foi desdobrada sempre que o fator níveis de esterco bovino apresentou significância estatística. Os níveis dentro de cada local de aplicação do adubo foram desmembrados nos seus componentes linear e quadrático, conforme Tabela 5. Quando aplicados abaixo da semente, observou-se efeito linear dos níveis crescentes do adubo, descrevendo uma equação $Y=28,68 x+741,35$. Quando se adubou ao lado da semente, o efeito dos níveis obedeceu a uma equação quadrática do tipo $\mathrm{Y}=-2,7064 \mathrm{x}^{2}+158,51 \mathrm{x}-254,56$.

A dose máxima para o máximo rendimento foi de 29,28 tha-1, quando aplicado ao lado da semente, alcançando-se uma produtividade de $2066,37 \mathrm{~kg}$ de algodão em caroço por hectare (Figura 2). A produtividade da linhagem de algodão colorido 
Tabela 5. Análise de regressão dos níveis de esterco dentro dos locais de aplicação nas variáveis rendimento em caroço $\left(\mathrm{kg} \mathrm{ha}^{-1}\right)$ do algodão BRS 200-marrom sob manejo orgânico

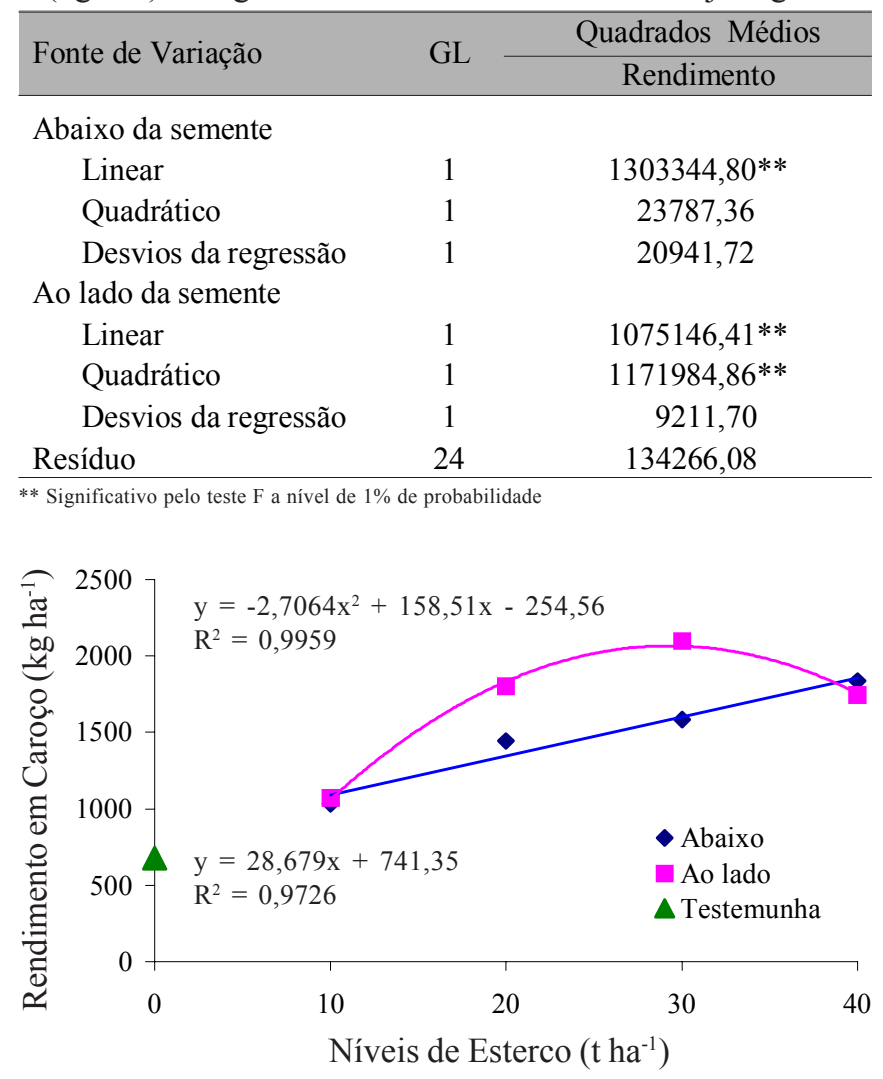

Figura 2. Rendimento em caroço do algodão BRS 200 marrom em função de níveis de esterco bovino
CNPA 95653 aumentou em 78\% quando se utilizaram 20 tha $^{-1}$ de esterco de curral (Beltrão et al., 2001). Na Califórnia, EUA, a produtividade de algodão (em caroço) irrigado cultivado sob manejo orgânico alcança entre 1100 a $1500 \mathrm{~kg} \mathrm{ha}^{-1}$ (Klonsky et al., 1996). A aplicação de adubos orgânicos é uma prática cara em razão da sua disponibilidade, transporte e mão-de-obra de aplicação, sendo oportuno que níveis menores promovam retorno econômico.

A maior eficiência da adubação orgânica com esterco bovino, quando aplicado ao lado da semente, talvez seja devida à arquitetura radicular do algodão que, segundo Magalhães et al. (1962) citados por Beltrão \& Melhorança (1998), apresenta quase $90 \%$ das suas raízes concentradas nos primeiros $15 \mathrm{~cm}$ do solo. $\mathrm{O}$ adubo nesta posição se localiza mais próximo da superfície, enquanto quando posicionado abaixo da semente está mais longe das raízes, principalmente neste tipo de solo, que favorece a lixiviação. Em níveis acima de $30 \mathrm{t} \mathrm{ha}^{-1}$, a aplicação de esterco ao lado das sementes promoveu decréscimos no rendimento do algodão, já que a proximidade entre as raízes e o adubo pode ter provocado toxicidade, resultado do excesso de amônia na atmosfera e de sais de potássio na solução do solo.

A análise de variância das variáveis relacionadas com a qualidade da fibra e do fio do algodão está disposta na Tabela 6, para os anos 2000, 2001 e 2002. No primeiro ano, as características da fibra não foram afetadas pelos tratamentos adotados; apenas a finura (MIC) no segundo ano, e o índice de fibras curtas (SFI) e uniformidade (UNF) no terceiro, foram influenciados pelos níveis de esterco bovino. Essas três

Tabela 6. Resumo das análises de variância das características tecnológicas de fibra [finura (I.M.), resistência (gf tex ${ }^{-1}$ ), comprimento (S.L.2,5\%), uniformidade de comprimento (\%), índice de fibra curta (\%), elongação (\%)] do algodão colorido BRS 200-marrom sob manejo orgânico, em função de níveis de esterco e locais de aplicação

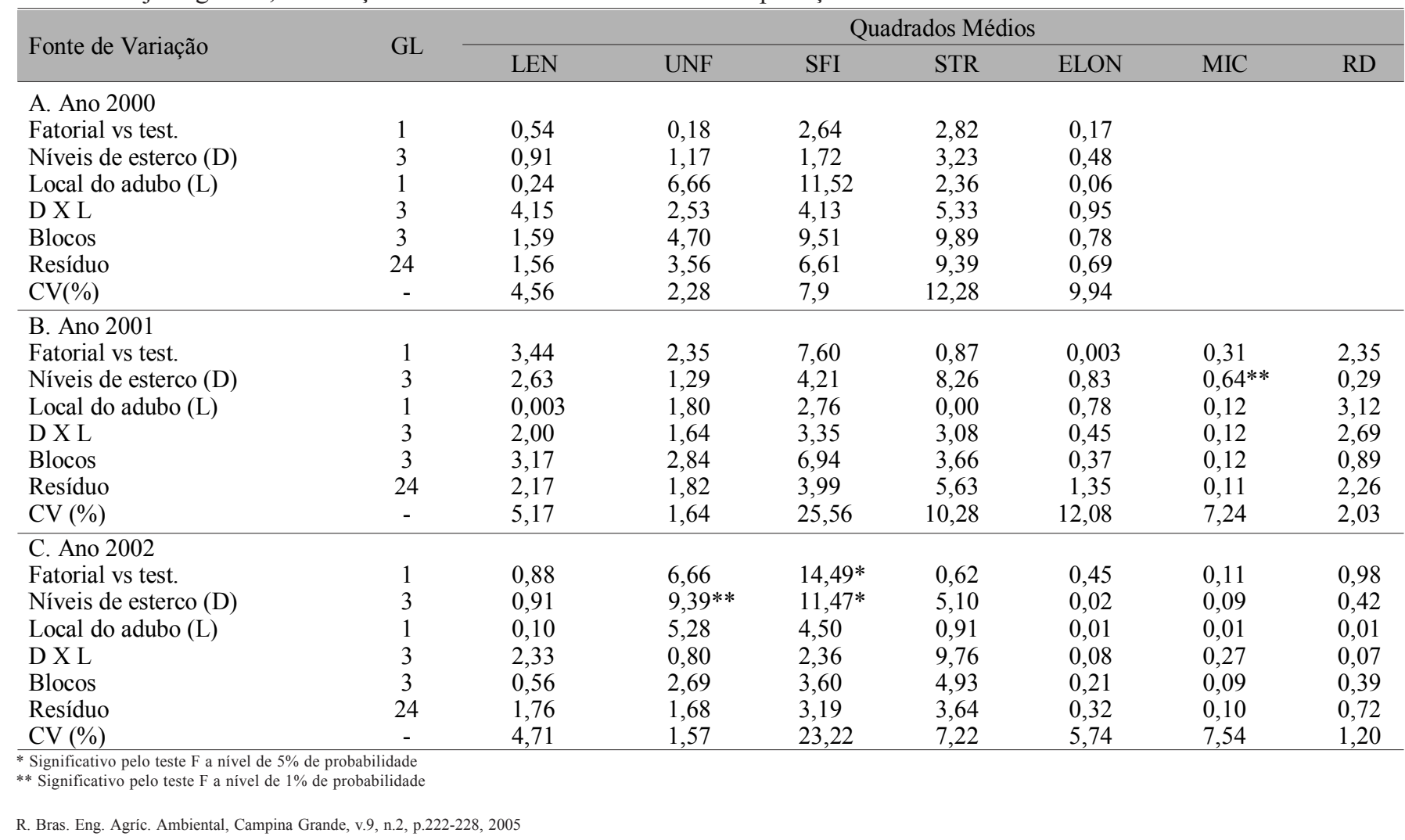




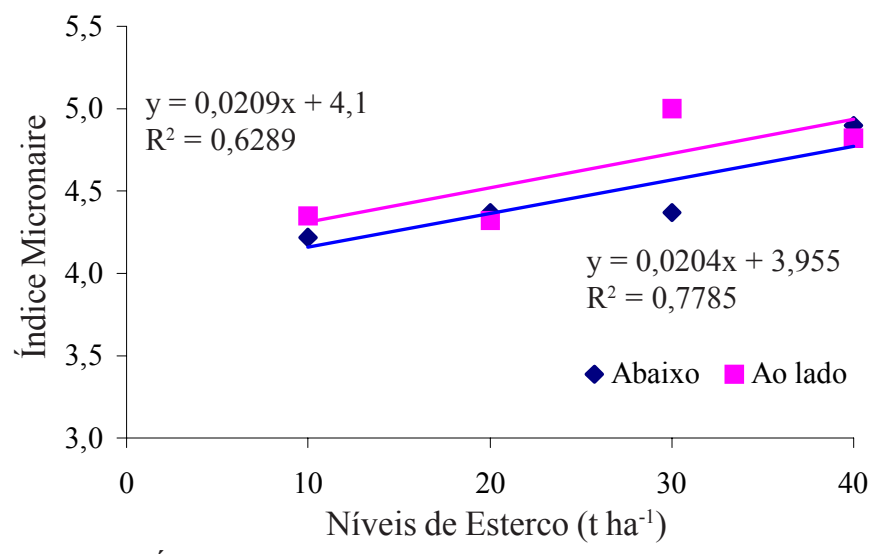

Figura 3. Índice Micronaire do algodão BRS 200 marrom em função de níveis de esterco bovino. Patos, 2001

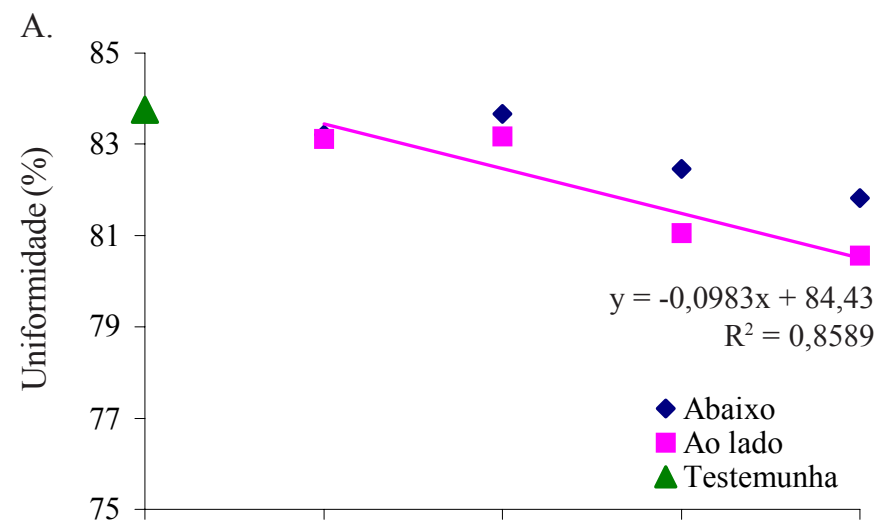

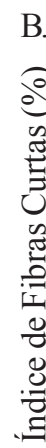

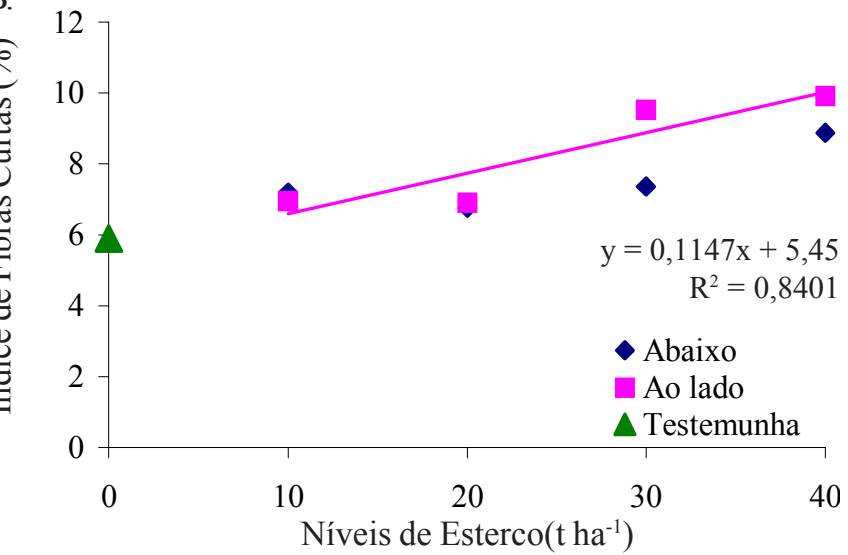

Figura 4. Uniformidade do comprimento (A) e Índice de fibras curtas (B) do algodão BRS 200 marrom em função de níveis de esterco bovino

variáveis foram submetidas a análise de regressão, estudandose cada nível do esterco bovino dentro dos dois locais de aplicação do adubo, mas apenas o índice de fibras curtas (SFI) no ano 2002 foi significativo a 5\% de probabilidade quando se estudou o contraste entre a testemunha absoluta (ausência de esterco) e o fatorial (presença de esterco) (Tabela 6C).

No ano 2002, verifica-se que a presença de adubo aumentou o índice de fibras curtas (SFI), o que deprecia a qualidade da fibra (testemunha sem adubo $=5,9$; fatorial com adubo $=7,93$ )

$\mathrm{O}$ efeito dos níveis de esterco sobre o índice micronaire (finura) foi significativo no ano 2001. Os valores desta variável aumentaram linearmente com o incremento dos níveis tanto quando o adubo foi aplicado abaixo, como ao lado da semente (Figura 3).

Quando o adubo foi aplicado ao lado da semente, as variáveis UNF e SFI apresentaram efeito linear em relação aos níveis aplicados (Tabela 7). Enquanto a uniformidade do comprimento das fibras decresceu com o aumento dos níveis, o índice de fibras curtas aumentou com o incremento do adubo (Figura 4A e B). Beltrão et al. (2001) verificaram respostas contrárias, já que a presença do esterco de curral melhorou a uniformidade das fibras na linhagem CNPA 95 653. As características da fibra do algodão são muito influenciadas pelas condições climáticas, fator que no semi-árido diverge muito de ano para ano.

Tabela 7. Análise de regressão dos níveis de esterco dentro dos locais de aplicação nas variáveis tecnológicas de fibra do algodão BRS-200 marrom sob manejo orgânico

\begin{tabular}{|c|c|c|c|}
\hline \multirow{2}{*}{ Fonte de Variação } & \multirow{2}{*}{ GL } & \multicolumn{2}{|c|}{ Quadrados Médios } \\
\hline & & UNF & SFI \\
\hline \multicolumn{4}{|l|}{ Abaixo da semente } \\
\hline Linear & 1 & 5,72 & 6,32 \\
\hline Quadrático & 1 & 1,21 & 3,90 \\
\hline Desvios da regressão & 1 & 1,05 & 0,01 \\
\hline \multicolumn{4}{|l|}{ Ao lado da semente } \\
\hline Linear & 1 & $19,40 * *$ & $23,33 * *$ \\
\hline Quadrático & 1 & 0,30 & 0,18 \\
\hline Desvios da regressão & 1 & 2,88 & 4,85 \\
\hline Resíduo & 24 & 1,68 & 3,19 \\
\hline
\end{tabular}

\section{CONCLUSÕES}

1. A adubação orgânica com esterco bovino incrementou o rendimento do algodão BRS 200; no entanto, a precipitação pluviométrica se constituiu no fator mais importante para o aumento de produtividade do algodão.

2. Quando ocorreu regularidade climática, a aplicação do esterco bovino ao lado das sementes foi mais eficiente, alcançando-se a máxima produtividade com aproximadamente 30 t ha $^{-1}$.

3. O índice macronaire em 2001, a uniformidade do comprimento e o índice de fibras curtas em 2002, foram as únicas características tecnológicas da fibra afetadas pelos níveis de esterco bovino adotadas.

\section{LITERATURA CITADA}

Altieri, M. A. Agroecologia: as bases científicas da agricultura alternativa. Rio de Janeiro: PTA/Fase, 1989, 240 p. Tradução de Patrícia Vaz. Agroecolgy: The scientific basis of alternativa agriculture.

Beltrão, N.E. de M.; Dantas, E.S.B.; Pereira, J.R.; Silva, C.A.D. da. Componentes para o cultivo orgânico do algodão perene colorido (marrom) no Nordeste brasileiro. V - Adubação orgânica e competição de plantas daninhas, linhagem CNPA 95 653. In: Congresso Brasileiro do Algodão, 3, 2001. Campo Grande, MS. Embrapa, Anais. Dourados: EMBRAPA: CNPA/ CNPAO, 2001. 1123p. 
Beltrão, N.E. de M.; Melhorança, A.L. Plantas daninhas: importância e controle. In: EMBRAPA. Centro de Pesquisa Agropecuária do Oeste (Dourados,MS). Algodão: informações técnicas. Dourados: Embrapa-CPAO/EmbrapaCNPA, 1998. 267p. Embrapa-CPAO. Circular Técnica,7

Bulluck, L.R.; Brosius, M..G.; Evanylo, K.; Ristaino, J.B. Organic and synthetic fertility amendments influence soil microbial, physical and chemical properties on organic and conventional farms. Applied Soil Ecology, Amsterdam, v.19, n.2, p.147-160, 2002.

Bulluck, L.R.; Ristaino, J.B. Synthetic and organic amendments affect southern blight, soil microbial communities and yield of processing tomatoes. Phytopathology, St. Paul, v.92, p.181-189, 2002

Buschle-Diller, G.; Knight, C.; Person, A.; Fox, S.V. Naturally colored cottons - shade changes upon wet treatments. In. Beltwide Cotton Conference, 1998, Memphis, Proceedings... Memphis: National Cotton Council of America, 1998, p.730732.

Doran, J. Building soil quality. In: Conservation Workshop on Opportunities and Challenges in Sustainable Agriculture, 1995. Red Deer, Canada. Alberta Conservation Tillage Society and Alberta Agriculture Conservation. Proceedings. Red Deer, Canada, 1995, p.151-158

Drinkwater, L.E.; Letourneau, D.K.; Workneh, F.; van Bruggen, A.H.C.; Shennan, C. Fundamental differences between conventional and organic tomato agroecosystems in California. Ecological Applications, Washington, n.5, p.1098$1112,1995$.

EMBRAPA - Empresa Brasileira de Pesquisa Agropecuária. Centro Nacional de Pesquisa de Solos. Sistema brasileiro de classificação do solos. Brasília: Serviço de Produção e Informação da Embrapa, 1999. 412p.

Ferreira, P.V. Estatística experimental aplicada à agronomia. Maceió: EDUFAL, 2000. 422p.

Freire, E.C.; Andrade, F.P. de; Farias, F.J.C.; Costa, J.N. da; Moreira, J. de A.N.; Vieira, R. de M.; Farias, R.H. de. Melhoramento do algodão colorido no Nordeste do Brasil. Campina Grande: EMBRAPA-CNPA, 1997. 6p. Pesquisa em Andamento, 49

Gill, J.L. Uses and abuses of statistical methods in research in parasitology. Veterinary Parasitology. Amsterdam, n.36. p.189-209, 1990.

Klonsky, K.; Tourte, L.; Swezey, S. Production practices and economic performance for organic cotton northern San Joaquin Valley-1995. In. Beltwide Cotton Conference, 1996, Memphis, Proceedings... Memphis: National Cotton Council of America, 1996, p.172-174.
Lima, H.V. de. Influência dos sistemas orgânico e convencional de algodão sobre a qualidade do solo no município de Tauá,CE. Fortaleza: UFC. 2001. 53p. Dissertação Mestrado Magalhães, A.C.; Fuzatto, M.G.; Gridi-Papp, I.L.; Schmidt, N. Desenvolvimento do sistema radicular do algodoeiro na camada arável do solo. Bragantia, Campinas, v.1, n.3, p.2130, 1962 .

Marquardt, S. Organic cotton: Production and market trends in the United States and Canada - 2001 e 2002. In. Beltwide Cotton Conference, 2003, Memphis, Proceedings... Memphis: National Cotton Council of America, 2003.

Medeiros, J. da C. Efeito da adubação do algodoeiro arbóreo precoce. In: EMBRAPA - Centro Nacional de Pesquisa de Algodão. Campina Grande - CNPA, 1991, p.388-389. Relatório Técnico Anual 1987-1989

Rajendran, A.T.P.; Venjglpalan, B.M.V.; Tarhalkar, C.P.P. Organic cotton cultivation in India - a culmination of non-chemical pest management. Acesso em 24/08/2003. Disponível em: $<$ http://www.indiaagronet.com/indiagronet/seeds/ organiccottonarticle-seeds.htm $>$

Santana, J.C.F.; Freire, E.C.; Wanderley, M.J.R.; Santana, J.C. da S.; Andrade, F. P. de; Andrade, J.E.O. de. Qualidade e tecnologia da fibra e do fio de linhagens de algodão de fibra colorida. Revista de Oleaginosas e Fibrosas. Campina Grande, v.3, n.3 p.195-200, 1999.

Santana, J.C.F. de; Wanderley, M.J.R.; Beltrão, N.E. de M. Tecnologia da fibra e do fio de algodão, análises e interpretação dos resultados. In: EMBRAPA. Centro de Pesquisa Agropecuária do Oeste (Dourados,MS). Algodão: informações técnicas. Dourados: Embrapa-CPAO/EmbrapaCNPA, 1998. 267p. Embrapa-CPAO. Circular Técnica,7

Silva, C.A.D. da. Seleção de isolados de Beauveria bassiana patogênicos ao bicudo-do-algodoeiro. Pesquisa Agropecuária Brasileira. Brasília, v.36, n. 2, p. 234-247, 2001.

Souto, P.C. Estudo da dinâmica de decomposição de estercos na recuperação de solos degradados no semi-árido paraibano. Areia: UFPB. 2002. 110p. Dissertação Mestrado

Stamatiadis, S.; Werner, M.; Buchnan, M. Field assessment of soil quallity as affected by compost and fertilizer application in a broccoli field. Applied Soil Ecology, Amsterdam, n. 12. p.217-225. 1999.

Stewart, B.A.; Robinson, C. Sustaining soil quality in dryland regions. Desertification Control Bulletin, Nairobi, n.28, p.24-27, 1996.

Swift, M. J. Towards the second paradigm: integrated biological manegement of soil. In: Siqueira, J.O.; Moreira, F.M.S.; Lopes, A.S.; Guilherme, L.R. G.; Faquin, V.; Furtini Neto, A.E.; Carvalho, J.G. (eds.) Inter-relação fertilidade, biologia do solo e nutrição de plantas: Lavras, SBCS; UFLA/DCS, 1999. Cap. I, p.11-24. 